\title{
Efficacy of extracorporeal shock wave therapy in the treatment of lateral epicondylitis
}

\author{
${ }^{1}$ Department of Physical Medicine and Rehabilitation, Izmir Katip Celebi University Faculty of Medicine, Izmir, Turkey; \\ 2Department of Physical Medicine and Rehabilitation, Usak State Hospital, Usak, Turkey; \\ ${ }^{3}$ Department of Physical Medicine and Rehabilitation, Malatya State Hospital, Malatya, Turkey
}

\begin{abstract}
OBJECTIVE: Lateral epicondylitis is one of the widely seen lesions of the arm characterized by pain localized over lateral epicondyle which is the insertion site of the wrist extensors, and extensor muscles of the forearm. It is easy to diagnose lateral epicondylitis but treatment involves some inherent drawbacks. Conservative management includes non-steroidal anti-inflammatory drugs, ultrasound therapy, steroid injections, functional bracing, laser therapy and extracorporeal shock wave therapy, however none of these modalities have been shown to be really effective based on evidence-based data. Our study is aimed to determine the efficacy of extracorporeal shock wave therapy (ESWT) therapy in the treatment of lateral epicondylitis.
\end{abstract}

METHODS: A total of 12 patients with the diagnosis of lateral epicondylitis were included in the study and 3 sessions of ESWT were applied (1 session per week). Maximum grip strength and pain scores were assessed before and at 1 . month after the treatment. Spesific tests for lateral epicondylitis were utilized and Turkish version of the Patient Rated Tennis Elbow Evaluation (PRTEE-T) questionnaire was administered and data obtained were analyzed.

RESULTS: Visual analog scale (VAS) scores were significantly lower $(p<0.05)$ and grip strength significantly increased $(p<0.05)$ one month after ESWT treatment. Overall PRTEE-T survey scores decreased significantly at first month $(p<0.001)$ after treatment. Patient's and physician's global self-assessment scores were significantly lower after treatment $(p<0.05)$.

CONCLUSION: To conclude, ESWT utilization in conservative treatment of lateral epicondyilitis was found to be effective on reducing pain, and improving functional activities and quality of life.

Key words: Conservative treatment; ESWT; lateral epicondylitis.

$\mathrm{L}$ ateral epicondylitis is one of the widely seen lesions of the arm characterized by pain localized over lateral epicondyle which is the insertion site of the wrist extensors, and extensor muscles of the forearm [1]. Its prevalence in general population ranges between 1-3\% which peaks between 40-50

Received: May 30, 2014 Accepted: June 16, 2014 Online: August 03, 2014

Correspondence: Hilal YESIL. Usak Devlet Hastanesi, Fiziksel Tip ve Rehabilitasyon Bolumu, Usak, Turkey.

Tel: +90232 - 3902432 e-mail: dradanur@yahoo.com

(c) Copyright 2014 by Istanbul Northern Anatolian Association of Public Hospitals - Available online at www.kuzeyklinikleri.com 
years of age $[2,3,4]$. It is seen more frequently in females, and more often affects the dominant hand $[2,3,4]$. Although its etiology is not known fully, reports indicate potential roles of aging, chemical, vascular, hormonal, and hereditary factors [5].

Lateral epicondylitis is frequently seen in individuals performing activities which repetitively strain extensor muscles of the wrist. It is characterized by pain, and decrease in grip strength which might manifest with resisted wrist extension, and extension of the middle finger accompanied with restriction of daily living activities [6]. Generally range of joint motion (ROM) is not affrected in lateral epicondylitis.

Increase in the severity of pain with palpation of the lateral epicondyle, and positivity of at least one of the tests which aggravate pain have diagnostic values [7]. A gold standard treatment modality for the management of lateral epicondylitis has not been found up to now owing to uncertainties in the etiology, and pathophysiology of the disease [8,9]. Basic principles of the treatment include pain relief, acceleration of the healing process, refraining from activities overloading arms, and patient's return to daily living activities. Conservative treatment alternatives include medical treatment, resting, use of splint, and orthosis, application of ice, electrotherapy, massage, manipulation-mobilization, exrcise, and extracorporeal shock wave therapy (ESWT) $[10,11,12]$.

Extracorporeal shock wave therapy has been reportedly successful in $48-73 \%$ of the cases with lateral epicondylitis who were refractory to other nonsurgical treatment alternatives [13]. Its noninvasive nature, and lower complication rates have increased its frequency of use. However, the mechanism of the symptomatic improvement achieved in lateral epicondylitis with shock waves, and its most effective curative doses have not been fully elucidated yet. This study has been planned to determine the efficacy of shock wave therapy in patients with the diagnosis of lateral epicondylitis.

\section{MATERIALS AND METHODS}

Our study was performed as a multi-centered prospective investigation aiming at determination of efficacy of shock wave therapy in the treatment of the patients with the diagnosis of lateral epicondylitis. After approval of the local ethics committee was obtained, a total of 12 patients aged between 35-80 years with the diagnosis of lateral epicondylitis who had not previously received shock wave therapy were included in the study. Exclusion criteria of our study were: presence of a different or multiple elbow problems, cervical or other upper extremity pathology, history of elbow joint operation, rupture of the elbow tendon, neurological affection, limited ROM of the joint because of known history of humerus, radius or ulnar fracture, pregnancy, hemostatic disorder, tumor or local or systemic infection of the upper extremity, and implanted pacemaker. The diagnosis of lateral epicondylitis was based on detailed physical examination, feeling of pain on the lateral side of the elbow, tenderness on lateral epicondyle, and clinical tests indicative of lateral epicondylitis $[14,15]$. Before initiating treatment, enlightened consent forms were obtained from the patients.

\section{Treatment}

Demographic data, duration of the disease, laterality of complaints, and sides of hand dominancy were recorded, and then a total of 3 sessions of shock wave therapy at weekly intervals were delivered using vibrolith ortho tip ESWT (ELMED Turkey) equipment. At each session shock wave therapy was applied on painful point $(\mathrm{s})(10 \mathrm{~Hz}$, 1.9 bar, 2000 shocks), using a electric gun with a R10 applicator tip and a skin protective gel. The application was well tolerated by the patients, any adverse effect (edema, pain etc) was not observed during the therapy, and none of the patients discontinued the treatment.

\section{Assessments}

Before the treatment, and at 1st month after the treatment using Jamar $^{\circledast}$ dynamometer maximum grip strength, and with visual analog scale (VAS) levels of patients' pain perception were evaluated. Mean values of 3 recurrent measurements performed using Jamar dynamometer (which displays 
grip force in pounds) while the patient was sitting erect, with his/her shoulder in adduction, elbow at $90^{\circ}$ flexion, supported forearm at midrotation, and wrist in neutral position, were recorded. Pain levels felt by the patients during resting, under slight pressure on the epicondyle, and activity were evaluated on a $10 \mathrm{~cm}$ long-horizontal VAS scale. A 10 $\mathrm{cm}$-long line was drawn, and the patients were requested to mark their perception level of pain on this line numbered from 0 to 10 at $1 \mathrm{~cm}$ intervals. Then patient's and the physician's global assessment scores, and duration of paracetamol use by the patients were inquired, and recorded. Besides, tests specific to lateral epicondylitis (Maudsley's, Mill's, and Thomsen's tests) were performed. For Thomsen's test, the patients were seated on a chair with their elbows supported with a cushion placed on a table. Shoulder joint was kept in a slight degree of flexion, and elbow joint positioned in extension. Forearm was placed in pronation, and wrist was flexed to nearly $30^{\circ}$. The patients were requested to extend their wrists, and asked to resist the forces exerted from the opposite direction. During this maneuver their feeling of pain was inquired. If pain was elicited during this manipulation, then the result of this test was considered to be positive. For Maudsley's test , the patients were positioned as in Thomsen's test, and requested to extend their middle fingers, Then the examiner pushed the 3 . finger down, and asked the patient to resist. If this manoeuvre was painful then the test result was considered to be positive.

In Mill's test, while the patient is seated on the chair, examiner standing behind the patient, positioned patient's shoulder at $90^{\circ}$ passive abduction, and elbow in extension, and with his/her free hand passively pronated and flexed patient's wrist. The patient was questioned if this manoeuvre elicited pain (positive test result). Then Turkish version of the Patient Rated Tennis Elbow Evaluation Test (PRTEE-T) which contains subgroups of pain, special activities, and daily living activities especially constructed for patients with lateral epicondylitis was applied [16]. PRTEE-T questionnaire form

TABLE 1. Demographic, and clinical features of the patients

\begin{tabular}{|c|c|c|c|}
\hline & $\mathrm{n}$ & $\%$ & Mean \pm SD \\
\hline Age (years) & & & $46.4 \pm 6.4$ \\
\hline \multicolumn{4}{|l|}{ Gender } \\
\hline Male & 5 & 41.7 & \\
\hline Female & 7 & 58.3 & \\
\hline Body mass index $\left(\mathrm{kg} / \mathrm{m}^{2}\right)$ & & & $28.6 \pm 3.1$ \\
\hline \multicolumn{4}{|l|}{ Occupation } \\
\hline Housewife & 5 & 41.7 & \\
\hline Retired & 4 & 33.3 & \\
\hline Overuse of upper extremity & 2 & 16.7 & \\
\hline Other (phone operator) & 1 & 8.3 & \\
\hline Sportive activities/hobbies requiring overuse of hands & 0 & 0 & \\
\hline Duration of the disease (months) & & & $3.5 \pm 3.2$ \\
\hline \multicolumn{4}{|l|}{ Dominant hand } \\
\hline Right & 12 & 100 & \\
\hline Left & 0 & 0 & \\
\hline \multicolumn{4}{|l|}{ Laterality of the painful side } \\
\hline Right & 10 & 83.3 & \\
\hline Left & 2 & 16.7 & \\
\hline
\end{tabular}


consists of 15 items which makes us understand patient's severity of pain, and amount of difficulties experienced because of his/her aching arm. It has two subscales specific to the patient as "Pain in the affected arm", and "Function of the affected arm". Total score is calculated by adding up pain and functional scores. Higher scores indicate increased pain, and functional disability ( $0=$ no disability $)$.

\section{Statistical evaluation}

For statistical analysis of data SPSS 14.01 program was used. In descriptive analysis, data were expressed as frequencies, ratios, and means, ( \pm standard deviation). Differences between pre, and post-treatment values were evaluated using paired samples t test. $\mathrm{P}<0.05$ was accepted as level of significance.

\section{RESULTS}

Seven female (58.3\%), and $5(41.7 \%)$ male patients were included in the study. Mean age, and body mass index of the patients were $46.4 \pm 6.4$ years, and $28.6 \pm 3.1 \mathrm{~kg} / \mathrm{m}^{2}$, respectively (Table 1 ). Right hand dominancy was detected in all patients. Mean duration of the disease was $3.5 \pm 3.2$ months. In 10 $(83.3 \%)$ patients lateral epicondylitis of the right elbow was noted (Table 1 ).

VAS scores of the pain elicited with resting, compression, and activity significantly decreased at posttreatment 1 . months when compared with pretreatment scores $(p<0.05)$. As assessed with Jamar dynamometer, handgrip strength scores significantly increased at posttreatment 1 . months relative to pretreatment values $(\mathrm{p}<0.05)$ (Table 2$)$.

Total score of the PRTEE-T questionnaire demonstrated a significant drop at first month after treatment relative to pretreatment score $(p<0.001)$. Patient's and physician's global posttreatment selfassessment scores also decreased significantly when compared with pretreatment values $(\mathrm{p}<0.05)$ (Table 2).

\section{DISCUSSION}

Even though the diagnosis of lateral epicondylitis is

TABLE2. Evaluation of pre-and post-treatment outcomes

\begin{tabular}{lllll} 
& & Mean \pm SD & $\mathrm{t}$ & $\mathrm{p}$ \\
\hline Handgrip strength & pret & $42.92 \pm 22.51$ & & \\
& postt 1. month & $58.75 \pm 21.23$ & 3.506 & $0.005^{* *}$ \\
Resting VAS & pret & $2.67 \pm 2.01$ & & \\
& postt 1. month & $1.17 \pm 1.27$ & 5.196 & $0.000^{* * *}$ \\
VAS with compression & pret & $8.42 \pm 0.90$ & & \\
& postt 1. month & $3.92 \pm 2.68$ & 5.817 & $0.000^{* * *}$ \\
VAS during activity & pret & $8.00 \pm 0.96$ & & \\
& postt 1. month & $4.92 \pm 1.92$ & 4.539 & $0.001^{* *}$ \\
Patient's global assessment & pret & $4.33 \pm 2.53$ & & \\
& postt 1. month & $2.92 \pm 1.44$ & 2.376 & $0.037^{*}$ \\
Physician's global assessment & pret & $3.58 \pm 0.79$ & & \\
& postt 1. month & $2.08 \pm 0.51$ & 6.514 & $0.000^{* * *}$ \\
PRTEE (Total score) & pret & $91.50 \pm 11.24$ & & \\
& postt 1. month & $55.83 \pm 11.69$ & 12.340 & $0.000^{* * *}$ \\
\hline
\end{tabular}

Pret: Pretreatment; Postt: Posttreatment; VAS: Visual analog scale; PRTEE: Patient Rated Tennis Elbow Evaluation.

*Difference between pre-, and post-treatment values $\mathrm{p}<0.05$, **Difference between pre-, and post-treatment values $\mathrm{p}<$.,01, ***Difference between pre-, and post-treatment values $p<0.001$. 
easily made, its treatment poses various difficulties. Choice of treatment differs in individual patients, and depends on personal experience of the physicians. Conservative treatment modalities such as, nonsteroidal anti-inflammatory drugs, ultrasonographic applications, steroid injections, functional bracing, physical therapy, laser therapy, and shock wave therapy have been used, but currently none of them is really efficacious as assessed by evidencebased data $[17,18]$.

In some studies performed, the efficacy of shock wave therapy in the treatment of lateral epicondylitis has been investigated, and success rates ranging between 68 and 91\% have been reported [19]. However some studies have indicated that shock wave therapy has either no therapeutic effect or been less effective than the placebo [20,21]. However we think that shock wave therapy will have an ameliorating effect on pain which has an impact on both quality of life of the patients, and their functional status. In our study, in the treatment of lateral epicondylitis, we observed short-term effectiveness of shock wave therapy on both subjective clinical parameters as VAS, patient's, and physician's global assessments scores, and PRTEE, and objective measurements as handgrip strength. However our study has limitations as scarce number of cases, and lack of a control group.

When we review the literature, in a pool analysis performed by Reza Nourbakhsh et al.[22] and Mehra et al.[23] concerning shock wave therapy, the authors reported $50 \%$ pain relief within 12 weeks of follow-up period with shock wave therapy. Spacca et al.[24] detected significant improvements with shock wave therapy in pain, and grip strength within 12 weeks of the follow-up period when compared with the placebo. Collins et al.[25] found significant decrease in pain aggravating with activity using shock wave therapy during 8 weeks of the follow-up period. The outcomes of all these studies are consistent with with ours, and follow-up periods of the studies indicating efficacy of shock wave therapy were generally shorter like ours. However in studies with longer follow-up periods the authors reported diverse outcomes. For example in high quality studies performed by Mehra et al. $(n=24)$ or Melikyan et al. $(n=74)$, the authors indicated lack of any difference between shock wave therapy, and placebo during 1st, 3rd, 6th and 12th month of the followup period [23, 26]. Again, in the year 2008, Staples et al. investigated short-, and long-term effectiveness of ultrasound-guided shock wave therapy on perception of pain, and functional status, and authors could obtain very few data supporting the use of shock wave therapy in the management of lateral epicondylitis [20]. Different outcomes retrieved with longer follow-up periods, suggest us a possible short-term efficacy of the shock wave therapy. Regarding this issue, meta-analyses, and systematic reviews should be performed which will analyze studies with different follow-up periods.

Some studies compared shock wave therapy with other treatment modalities. For example in a randomized controlled trial performed with 93 patients, the authors indicated that pain scores significantly decreased in the injection group when compared with the shock wave therapy group after 3 months follow-up period but the outcomes did not remain the same after 6 months follow-up period [27]. In a randomized controlled study performed more recently by Gündüz et al., shock wave therapy was compared with hot pack, ultrasound, and friction-massage therapies, and any significant intergroup difference was not reported as regarding pain scores, and grip strength [27]. When we reviewed the literature, we observed use of various rating scales, and methods of measurement. Therefore, for healthy comparisons between shock wave therapy, and other modalities, survey studies, and meta-analyses should be performed on diverse studies using standardized assessment methods.

In addition to all of these abovementioned points, diverse outcomes can be obtained based on the dose delivered during the shock wave therapy, and the equipment used. For example in a systematic analysis published in 2007, it was reported that types of device (electromagnetic, radial), treatment doses, intensity, and number of shock waves delivered per unit time differed among studies. The authors also emphasized that in absolutely, and precisely indicated cases shock wave therapy can be effective, and be tried preoperatively in patients 
refractory to other treatment modalities [28].

When we reviewed the literature we noted use of various measurement, and evaluation methods.. Use of various methods can yield controversial outcomes. Therefore we think that with randomizedcontrolled studies performed in the future with larger-scale patient population using standardized measurement, and assessment methods, the efficacy of shock wave therapy in the treatment of lateral epicondylitis can be better elucidated.

Conflict of Interest: No conflict of interest was declared by the authors.

Financial Disclosure: The authors declared that this study has received no financial support.

\section{REFERENCES}

1. Stasinopoulos D, Johnson MI. Cyriax physiotherapy for tennis elbow/lateral epicondylitis. Br J Sports Med 2004;38:675-7.

2. Kamien M. A rational management of tennis elbow. Sports Med 1990;9:173-91. CrossRef

3. Nirschl RP. The etiology and treatment of tennis elbow. J Sports Med 1974;2:308-23. CrossRef

4. Meyer NJ, Walter F, Haines B, Orton D, Daley RA. Modeled evidence of force reduction at the extensor carpi radialis brevis origin with the forearm support band. J Hand Surg Am 2003;28:279-87. CrossRef

5. Nirschl RP, Pettrone FA. Tennis elbow. The surgical treatment of lateral epicondylitis. J Bone Joint Surg Am 1979;61:832-9.

6. Nordin MFV. Basic biomechanics of the musculoskeletal system. 3rd ed. Lippincott Williams \& Wilkins; 2001. p. 340-57.

7. Vicenzino B. Lateral epicondylalgia: a musculoskeletal physiotherapy perspective. Man Ther 2003;8:66-79. CrossRef

8. Howitt SD. Lateral epicondylosis: a case study of conservative care utilizing ART and rehabilitation. J Can Chiropr Assoc 2006;50:182-9.

9. Labelle H, Guibert R, Joncas J, Newman N, Fallaha M, Rivard $\mathrm{CH}$. Lack of scientific evidence for the treatment of lateral epicondylitis of the elbow. An attempted meta-analysis. J Bone Joint Surg Br 1992;74:646-51.

10. Sevier TL, Wilson JK. Treating lateral epicondylitis. Sports Med 1999;28:375-80. CrossRef

11. Kochar MDA. Effectiveness of a specific physiotherapy regimen on patients with tennis elbow. Physiotherapy 2002;88:333-4.

12. Chan HL, Ng GY. Effect of counterforce forearm bracing on wrist extensor muscles performance. Am J Phys Med Rehabil 2003;82:290-5. CrossRef
13. Ogden JA, Alvarez RG, Levitt R, Marlow M. Shock wave therapy (Orthotripsy) in musculoskeletal disorders. Clin Orthop Relat Res 2001;387:22-40. CrossRef

14. Kalyon TA. Ultrason. In: Tuna N, editor. Elektroterapi. 2nd ed. Istanbul: Nobel Tip Kitabevleri; 2001. p. 129-40.

15. Pienimäki T, Tarvainen T, Siira P, Malmivaara A, Vanharanta H. Associations between pain, grip strength, and manual tests in the treatment evaluation of chronic tennis elbow. Clin J Pain 2002;18:164-70. CrossRef

16. Altan L, Ercan I, Konur S. Reliability and validity of Turkish version of the patient rated tennis elbow evaluation. Rheumatol Int 2010;30:1049-54. CrossRef

17. Boyer MI, Hastings H 2nd. Lateral tennis elbow: "Is there any science out there?". J Shoulder Elbow Surg 1999;8:481-91. CrossRef

18. Theis C, Herber S, Meurer A, Lehr HA, Rompe JD. Evidencebased evaluation of present guidelines for the treatment of tennis elbow-a review. [Article in German] Zentralbl Chir 2004;129:252-60. [Abstract] CrossRef

19. Wang CJ. Extracorporeal shockwave therapy in musculoskeletal disorders. J Orthop Surg Res 2012;7:11. CrossRef

20. Staples MP, Forbes A, Ptasznik R, Gordon J, Buchbinder R. A randomized controlled trial of extracorporeal shock wave therapy for lateral epicondylitis (tennis elbow). J Rheumatol 2008;35:2038-46.

21. Buchbinder R, Green SE, Youd JM, Assendelft WJ, Barnsley L, Smidt N. Shock wave therapy for lateral elbow pain. Cochrane Database Syst Rev 2005;4:CD003524.

22. Reza Nourbakhsh M, Fearon FJ. An alternative approach to treating lateral epicondylitis. A randomized, placebo-controlled, double-blinded study. Clin Rehabil 2008;22:601-9. CrossRef

23. Mehra A, Zaman T, Jenkin AI. The use of a mobile lithotripter in the treatment of tennis elbow and plantar fasciitis. Surgeon 2003;1:290-2. CrossRef

24. Spacca G, Necozione S, Cacchio A. Radial shock wave therapy for lateral epicondylitis: a prospective randomised controlled single-blind study. Eura Medicophys 2005;41:17-25.

25. Collins EDH, Jafarnia KK. A clinical study of extracorporeal shock waves (ESW) for treatment of chronic lateral epicondylitis. Current Orthopaedic Practice 2011;22:185-92. CrossRef

26. Crowther MA, Bannister GC, Huma H, Rooker GD. A prospective, randomised study to compare extracorporeal shockwave therapy and injection of steroid for the treatment of tennis elbow. J Bone Joint Surg Br 2002;84:678-9. CrossRef

27. Gündüz R, Malas FÜ, Borman P, Kocaoğlu S, Özçakar L. Physical therapy, corticosteroid injection, and extracorporeal shock wave treatment in lateral epicondylitis. Clinical and ultrasonographical comparison. Clin Rheumatol 2012;31:807-12. CrossRef

28. Rompe JD, Decking J, Schoellner C, Theis C. Repetitive lowenergy shock wave treatment for chronic lateral epicondylitis in tennis players. Am J Sports Med 2004;32:734-43. CrossRef 